\title{
Más que un drama histórico: Comentario dramatológico de Fuerte Bulnes (1955) de María Asunción Requena ${ }^{1}$
}

\author{
More than a historical drama: \\ Dramatological commentary on Fuerte Bulnes (1955) \\ by María Asunción Requena \\ Juan Pablo Amaya González \\ Universidad del Bío-Bío, Chile, $\varangle$ jpamaya@ubiobio.cl \\ [orcid.org/0000-0002-3240-5948]
}

\section{RESUMEN}

Este artículo realiza un análisis dramatológico a la obra Fuerte Bulnes de María Asunción Requena. El objetivo es destacar los aportes de la dramaturga en la construcción de la identidad nacional, con la incorporación de otras historias ausentes del relato central hegemónico. Mediante los elementos fundamentales del teatro propuesto por García Barrientos: tiempo, espacio, personaje y visión, se subrayan las partes centrales que conforman este drama histórico. Los resultados del análisis refuerzan el imaginario del sur de Chile en forma épica, en que se ponen a la vista otras historias y los esfuerzos de hombres y mujeres que el centralismo ha querido dejar afuera.

PALABRAS CLAVE: Fuerte Bulnes, María Asunción Requena, drama histórico, drama de personajes, dramatología.

\section{ABSTRACT}

This article makes a dramatological analysis on Fuerte Bulnes by María Asunción Requena. Its objective is to highlight the contribution of this dramatist in the formation of national identity, with the inclusion of facts which are absent in the central hegemonic history. Thanks to the fundamental elements of theatre proposed by García Barrientos:

$1 \quad$ El artículo forma parte de la tesis doctoral titulada "La trilogía del sur de María Asunción Requena: dramaturgia para otra nación chilena y otra literatura nacional”, defendida en la Universidad de Concepción el año 2017. Ha sido actualizado en el marco del proyecto Fondecyt Postdoctorado No 3190586, titulado "Geografías teatrales: el país de las mujeres. (Dramaturgas chilenas del periodo 1941 a 1973)”. 
time, space, character and vision; the central parts which form this historical drama are emphasized. The results of the analysis strengthen the imaginary of Southern Chile in an epic manner, which considers other facts and the efforts made by men and women, which centralism has chosen to leave out.

KEY WORDS: Fuerte Bulnes, María Asunción Requena, historical drama, characters drama, dramatology.

\title{
LA ESCRITURA DRAMÁTICA DE MARÍA ASUNCIÓN REQUENA
}

\author{
"Va siendo hora de comprendernos desde aquellos \\ territorios geográficos y culturales no metropolitanos que \\ la "gran historia" nacional sistemáticamente ha obliterado"
}

(Sergio Mansilla)

Durante tres décadas, el gran proyecto dramatúrgico de María Asunción Requena (19111986) se expresa en una trilogía de profunda relación con la historia de Chile y los territorios australes: Magallanes, Aysén y Chiloé.

Sus padres eran españoles, nació en Argentina y se nacionalizó chilena. En su personalidad, supo armonizar la profesión de dentista con sus intereses literario/teatrales. Punta Arenas ${ }^{2}$ fue su ciudad de residencia gran parte de su vida familiar y profesional. Desarrolló un trabajo particular dentro de la literatura, porque su obra escrita desde el sur de Chile, alejada de la metrópolis de producción cultural, logró ser reconocida dentro de una generación y aceptada para ser parte de las representaciones programadas, tanto por grupos profesionales como vocacionales, en el contexto de la revitalización del teatro nacional.

Ubicada por la crítica en la generación del 50', hombres y mujeres de teatro, sensibilizados por la experiencia y consecuencias de la Segunda Guerra Mundial, buscaron una expresión dramatúrgica que explorara las posibilidades de las identidades nacionales. Dentro del listado de nuevos dramaturgos y dramaturgas, el nombre de Requena es acompañado por el de Gabriela Roepke (1920-2013) e Isidora Aguirre (1919-2011). Las tres dramaturgas, al igual que sus contemporáneos Egon Wolff (1926-2016), Sergio Vodanovic (1926-2001), Luis Alberto Heiremans (1928-1964), por nombrar algunos, se destacaron por creer que el teatro chileno necesitaba nuevos aires gracias a un trabajo colaborativo, no solo en la creación, sino que también en la producción, representación y difusión.

En 1941, bajo el amparo de la institución universitaria, se creó el Teatro Experimental de la Universidad de Chile. Posteriormente, nuevos grupos son conformados en el contexto

Si bien María Asunción Requena nació en Argentina, ella y su hermano "se nacionalizaron chilenos, pero sus padres deciden enviarlos a estudiar humanidades a Alicante (España)" (Luzanto, 1994, p. 183), lo que revela, por un lado, su filiación de ascendencia española y, por otro, su formación europea en cultura clásica y occidental. 
de la Universidad Católica, Universidad de Concepción, Universidad Técnica del Estado, Universidad de Antofagasta, junto a grupos vocacionales de auto-organización; todos ellos buscaron la "difusión del teatro clásico y moderno, formación del teatro escuela, creación de un ambiente teatral, presentación de nuevos valores"3 (Durán-Cerda, 1970, p. 18). Así, nuevos grupos, actores, directores, dramaturgos, encaminaron sus esfuerzos "hacia el afán de incorporar al teatro chileno una atmósfera alegórica, de alta ficción poética, de fantasía, de ensueños, de personajes interesantes, de acontecimientos mágicos” (p. 24).

En este nuevo ambiente literario y teatral, se da el trabajo de María Asunción Requena, principalmente, su reconocida trilogía del sur: Fuerte Bulnes (1955), Ayayema (1964), Chiloé, cielos cubiertos (1972). Sus obras gozaron de éxito teatral (Villegas, 1995) y, en particular, la trilogía tuvo amplia aceptación en la cartelera teatral como analizó Patricia Henríquez (2010) a partir de la representación de Ayayema por el Teatro de la Universidad de Concepción (TUC), es un esfuerzo por escenificar los conflictos de una zona geográfica que no tiene mayor representación literaria, menos teatral. Hasta el momento, las historias de la literatura chilena solo recogen un limitado conjunto de imágenes del sur como los escenarios narrativos de Francisco Coloane y, por otro lado, se han olvidado los personajes en las soledades de la pampa magallánica y los archipiélagos narrados por Edesio Alvarado ${ }^{5}$, solo por dar ejemplos.

Fuerte Bulnes es un "drama que reconstruye un episodio estimulante, la existencia heroica de los hombres y mujeres que incorporaron al territorio de la República la inhóspita, pero opulenta región de Magallanes, a mediados del siglo XIX" (Durán-Cerda, p. 29). Una línea parecida, se continúa en Ayayema, obra que "confronta dos mundos en crisis, por un lado los aspectos contradictorios del hombre contemporáneo y, por el otro, la mentalidad más primaria que todavía existe en Chile, los alacalufes" (p. 30). Chiloé, cielos cubiertos condensa sus esfuerzos dramatúrgicos anteriores en una síntesis de la realidad chilota; su nombre "obedece al tic del pronóstico del tiempo en la capital, que siempre anuncia nublados para esa isla. Pero es, también, el vaticinio respecto de la condición de esa región sureña, una situación carente de sol o de horizontes abiertos" (Piña, 2008, pp. 9-10).

3 La expresión nuevos valores hace referencia a incorporar el trabajo de nuevos dramaturgos y dramaturgas, así como de creadores en todas las áreas del quehacer teatral. Se incentivó la escritura con concursos literarios, que premiaban la publicación de las obras y, en el mejor de los casos, con el montaje dentro de la temporada oficial de la compañía universitaria.

$4 \quad$ Villegas afirma que la obra de Requena es un "caso interesante de la historia literaria, aunque bastante común dentro de la historia del teatro: el éxito como autora teatral y poca presencia en las historias literarias" (p. 19), producto del discurso crítico hegemónico construido de modo central y homogeneizador para la vasta producción literaria del territorio nacional.

5 Aparte de los cuentos de Coloane ambientados en los canales australes o en las estancias magallánicas, es importante destacar su obra dramática La Tierra del Fuego se apaga (1945), luego filmada bajo la dirección de Emilio Fernández en 1955. En narrativa, la novela El desenlace (1966) de Edesio Alvarado mostró la vida en la Patagonia bajo el lente del relato policial. Ambas obras son ejemplos significativos de la amplia e importante producción literaria de Aysén y Magallanes soslayada por las historias nacionales de la literatura. Valga aquí el aporte sistemático de la Dra. Mábel Arratia en Fundación narrativa de la Patagonia (2011), en que ofrece una mirada temática amplia de los textos literario/narrativos fundacionales del territorio austral para construir una historia literaria renovadora e inclusiva. 


\section{EL MÉTODO DE ANÁLISIS: COMENTARIO DRAMATOLÓGICO}

La dramatología es un marco teórico formulado por José Luis García Barrientos. Su trabajo teórico destaca dentro de las propuestas de análisis de las obras teatrales porque propone un método de análisis "que valga lo mismo para los textos dramáticos que para los espectáculos teatrales, para las obras puestas en libro igual que para las puestas en escenas” (2012, p. 33). Bautizó su propuesta como dramatología, siguiendo el modelo narratológico de Genette, con el fin de superar la dicotomía tradicional que define teatro como la suma de texto más espectáculo (Villegas, 1971).

La dramatología es "la teoría del drama (...), es decir, del modo dramático, o, si se quiere, el estudio de las posibles maneras de disponer una historia para su representación teatral" (García Barrientos, p. 41). En su libro Cómo se comenta una obra de teatro (2012), explica y fundamenta la dramatología como método de análisis para el comentario teatral y es complementado en otro texto de aplicación del método por otros investigadores: Análisis de la dramaturgia: nueve obras y un método (2007).

El comentario dramatológico se encuentra vigente, en tanto, como reconoce Abraham, "se transforma en instrumento al servicio de la crítica y se utiliza para indagar diversas dramaturgias” (2015, p. 115). Quizá por esto, los libros de García Barrientos han tenido múltiples reediciones, fuera de España e incluso traducciones al francés y árabe ${ }^{6}$.

Para el comentario dramatológico de Fuerte Bulnes, se considera la obra de Requena como texto dramático en su codificación literaria, pues posee "una cierta autonomía representativa respecto al teatro de la que el "texto" carece. Tal autonomía permite acceder al drama a través de su lectura, es decir, de la experiencia genuinamente literaria” (García Barrientos, p. 39). Este valor literario de las obras teatrales escritas en el marco de los teatros universitarios fue alcanzado como consecuencia de la promoción de nuevas escrituras, las que fueron premiadas con reconocimientos materializados en premios y/o estrenos como el concurso anual de obras teatrales organizado por el Teatro Experimental o el Premio Municipal de Teatro que recibió la misma Requena por la obra mencionada (Cánepa, 1966; Fernández, 1976).

Con la imposibilidad de restituir la escenificación de las obras en estudio, debido a lo efímero de la representación teatral y la distancia temporal con los montajes, la obra

$6 \quad$ Se le reconoce al método "su decidida apuesta por la claridad expositiva, la coherencia terminológica y la precisión conceptual en franca oposición a la vaguedad” (Carrera, 2014, p. 232). Ha permitido el estudio de la dramaturgia escrita en lengua española, sus comentarios han sido publicados en una serie de análisis de teatro español y latinoamericano: Análisis de la dramaturgia cubana actual (2013), La razón pertinaz. Teoría y teatro actual en español (2014), Análisis de la dramaturgia argentina actual (2015), Análisis de la dramaturgia española actual (2016), Análisis de la dramaturgia uruguaya actual (2018).

Los distintos autores que emprenden los análisis que componen los libros citados demuestran que "el método no es un modelo de lectura monolítico, sino que se concibe como un punto de partida para establecer los cimientos sobre los que fundar un comentario teatral” (Olivares, 2008, p. 275) y, por lo tanto, se adecua a las necesidades de investigación y análisis. El comentario es parcial, pero permite abordar distintos aspectos en que se desenvuelve la práctica teatral. 
dramática adquiere más importancia, porque se configura en casi el único recurso para testimoniar el teatro del pasado.

El análisis se estructura a partir de los elementos fundamentales del drama: espacio, tiempo, personaje y público. Estos cuatro elementos se desprenden de la definición: lo que ocurre entre unos personajes en un espacio y durante un tiempo ante un público (García Barrientos, p. 45).

El comentario dramatológico se inicia con atención a la estructura del drama; en concreto, se revisan las funciones que cumplen los diálogos y las acotaciones, en tanto, son la concreción de la doble enunciación teatral: "aquella en la que interactúan los actores/personajes y aquella en que esa actuación se orienta a (es para) el público” (García Barrientos, 2018, p. 32).

Si bien la forma más frecuente del diálogo es el coloquio entre dos o más personajes, importa revisar si existen otras formas como el soliloquio, monólogo, aparte o apelación; junto con determinar qué funciones teatrales cumplen. De las acotaciones, es necesario determinar a qué nivel dramático, extradramático o metadramático hacen referencia, pues revelan la configuración del mundo ficcional y el dominio que el dramaturgo tiene en esa construcción.

En este mismo nivel, el análisis se pregunta por cuáles son las estructuras elegidas por el dramaturgo para la ficción dramática. Principalmente, las categorías involucradas son aquellas referidas a las secuencias (acto, escena, cuadro), el tipo de drama (de acción, personaje o ambiente).

Bajo la categoría de Tiempo, se analiza el modo en que se relacionan los dos planos temporales: el tiempo de la fábula (diegético) y el tiempo de la representación (escénico). El dramaturgo recurre a recursos de ordenación de las escenas, la frecuencia de escenificación de las mismas; así como, de su duración, velocidad, ritmo producto de recursos como las pausas, saltos temporales, resúmenes. Todo lo anterior, permite clasificar las obras según la distancia que el lector/espectador establece con el tiempo de la fábula, posible en tres tipos de drama: histórico, contemporáneo, futurario.

La categoría Espacio considera tanto el espacio de la comunicación, la configuración de la sala para la representación, como el espacio de la ficción que ocurre la acción. En este plano, el objetivo es descubrir el o los modos en que se diseña el decorado, iluminación, accesorios, sonidos, música, maquillaje, movimientos, etc. En su conjunto, es posible significar el espacio y reconocerlo cercano o alejado del realismo.

El estudio de los personajes se inicia con la revisión de todos quienes participan de la acción (reparto), para, a continuación, clasificarlos según el grado de participación (configuración). Este análisis permite distinguir sus niveles de compromiso con el desarrollo y desenlace del conflicto.

Un buen nivel de caracterización de los personajes permite determinar si corresponden a personajes idealizados, humanizados o degradados. Frecuentemente, en consonancia con el tipo de drama presentado según el tiempo y el espacio. 
En las tres categorías de análisis -tiempo, espacio y personajes- se comparten los conceptos de análisis: patente, latente, ausente. Esto se debe a que no solo se considera aquello que es representado en el escenario y visible para los espectadores (patente), sino que también se evidencia aquello que es contiguo al escenario, visto por los personajes (latente). Lo ausente corresponde aquello distinto al aquí y el ahora del tiempo de la ficción, por lo tanto, ausente para los personajes/espectadores.

Finalmente, la última categoría de análisis de la dramatología es la visión, vinculada directamente con el público. Por ello, considera el reconocimiento de los grados de distancia establecidos entre "el plano representante y el representado" (García Barrientos, 2018, p. 49), por lo tanto, relacionado a los extremos de la ilusión de realidad; así como, de la perspectiva subjetiva de quienes participan como espectadores y, por consiguiente, sujetos sensitivos, cognitivos y afectivos.

\section{Fuerte Bulnes}

Fuerte Bulnes es la primera obra dramática de la "trilogía del sur" de María Asunción Requena, con la que quiere escenificar los conflictos más significativos de una parte de la geografía nacional, en su relación histórica con la conformación del país. Por ello, no es extraño que este comienzo tenga como asunto la geografía más austral de Chile y represente un momento histórico de los albores de la constitución de la República, permanentemente soslayado de la historiografía nacional. Sus siguientes obras avanzan geográficamente hacia el norte y hacia la contemporaneidad.

La dramaturga conoce bien los hechos históricos que incorporan la zona de Magallanes al territorio nacional, algunos años después de proclamada la independencia. Tantos los hechos como los personajes históricos de la Fundación del Fuerte Bulnes en 1843 por orden del Presidente Manuel Bulnes, quien acoge el consejo de Bernardo O’Higgins, son asunto para su escritura dramática.

\section{Escritura, dicción y ficción dramática}

Requena estructura su obra en tres actos, sin distinción de escenas para cada uno. Su elección viene a significar un manejo clásico de las estructuras dramáticas, pues cada acto ha sido limitado en función de una jornada o día. En conjunto, los tres son la progresión lineal del conflicto desde su presentación, desarrollo y desenlace, más un epílogo que viene a funcionar como cierre discursivo del significado histórico de los hechos acontecidos y la expresión ideológica de la representación teatral/literaria.

La unidad de acción como consecuencia del tratamiento de un solo conflicto -la imposibilidad de los colonos chilotes de cumplir la misión de hacer patria en las condiciones más adversas- se corresponde con la unidad de espacio. La obra posee un gran cuadro: los 
espacios exteriores y comunitarios del fuerte.

En su aspecto global, la obra puede ser clasificada como un drama de ambiente, en consideración a que el Fuerte Bulnes ocupa el primer plano. Quizá sea este aspecto el que ha llevado a la crítica a nominarla drama histórico: obra de recuperación histórica y folclórica (Piña, 2014), de valoración del pasado histórico (Durán-Cerda, 1070; Muñoz \& Oelker, 2014), estimulada "por el abundante caudal anecdótico de la historia nacional” (Durán-Cerda, 1963, p. 192).

Sin embargo, no se puede soslayar la vital importancia de los personajes que construyen y habitan ese ambiente, pues como reconoció Castedo-Ellerman, "concibe un número de tipos humanos, arquetipos numantinos"7 (1982, p. 104). Hay aquí una profundización de los conflictos humanos que afectan a los colonos y su sujeción contractual con la República que los ha comisionado. En muchas ocasiones, las individualidades de los personajes se unen para actuar como grupo y reclamar el abandono en que se encuentran; estas acciones hacen recordar una constante de la dramaturgia de los teatros universitarios: la representación de amplios sectores marginados de la sociedad y que actúan en conjunto para exigir derechos. Así ocurre en Los Papeleros (1962) de Isidora Aguirre, Los Invasores (1963) de Egon Wolff, y que retrotrae al teatro clásico español de Fuenteovejuna (1613) de Lope de Vega.

Respecto de la escritura dramática propiamente tal, esto es diálogo más acotaciones, ambas se presentan en equilibrio clásico. Los personajes interactúan por medio del diálogo, siempre entre dos o más personajes, con lo que no hay uso de formas como el soliloquio, monólogo y, menos aún, del aparte, que rompería la ilusión de realidad al apelar al público.

El diálogo asume múltiples funciones, principalmente, dramática al dar cuenta de la vida pública de los personajes de Fuerte Bulnes; en menor grado, da cuenta de la vida íntima, como ocurre en la relación amorosa de Sebastián y la indígena Onahe.

También el diálogo asume la función caracterizadora, la que permite conocer los rasgos y comportamientos de los personajes, así como del espacio. Finalmente, una función ideológica o didáctica en el epílogo, en que se refuerza la importancia de Magallanes para la nación chilena y el olvido a que ha estado sometida.

Las acotaciones se caracterizan por ser impersonales y por cumplir una función representativa. Son esencialmente dramáticas, pues indican movimientos y acciones de los personajes, tanto como indicaciones sobre el espacio.

Solo en determinados momentos, hay acotaciones extradramáticas, aquellas que aluden a la escenificación como en "iluminándose el camino con chonchones que proyectan una luz triste sobre el escenario" (Requena, 1979, p. 168), y en el epílogo "Al encenderse las luces” (p. 196).

La historiografía crítica de Castedo-Ellerman difiere de la crítica tradicional, en tanto matiza la afirmación de drama histórico. Es así, como el adjetivo numantino resulta sugestivo porque desde la comparación con la obra La destrucción de Numancia (1582-1585) de Miguel de Cervantes abre la interpretación al carácter colectivo del drama, pero además el final trágico de la inmolación del pueblo ibérico como resistencia a la invasión romana es similar al sacrificio de Benamina y a la destrucción del fuerte por el fuego. 
Las acotaciones dramáticas son principalmente de tipo personales y espaciales. Las personales nombran a los personajes (nominativas); dan cuenta de susurros, cantos, gritos (paraverbales); dan cuenta del cuerpo, de la psicología y de los movimientos (operativas). Las acotaciones espaciales se encuentran en los inicios de cada acto y epílogo, junto a otras dentro de los actos.

La riqueza de las acotaciones y su justa medida, acompaña de modo preciso los diálogos. Otorga a la obra la virtualidad teatral necesaria para su configuración como obra dramática, por lo tanto, literaria.

La enorme cantidad de acotaciones dramáticas por sobre la exigua presencia de acotaciones extradramáticas viene a significar el dominio amplio de la dramaturga sobre la configuración literaria de la obra, así como también del reconocimiento del rol del director teatral, figura que participa también como creador al momento de la puesta en escena, responsabilidad adquirida con las innovaciones formales impulsadas por los teatros universitarios.

\section{Tiempo}

Desde la categoría del tiempo, Fuerte Bulnes es la representación de los años de vida del proyecto colonizador de Magallanes, esto es, desde las cartas de O’Higgins en que pedía colonizar el sur, pasando por la construcción y zarpe de la goleta Ancud, fundación del fuerte y el traslado a Punta Arenosa (Sandy Point).

Como se ve, el tiempo diegético o de la fábula es mayor a las posibilidades ajustadas del tiempo de la escenificación, por lo tanto, la dramaturga configuró una obra dramática por medio de la condensación y la elipsis. Primero, condensa el tiempo diegético a partir de la representación de algunos días de la vida del fuerte: el día de visita del capitán Williams poco después de la fundación en el acto primero, algunos días en otros años hacia el cierre del fuerte. Segundo, cada acto corresponde a un tiempo diferente y el paso entre ellos se da por la simple elipsis, una interrupción con salto implícito en el tiempo de la fábula.

El tiempo diegético es conocido por el lector/espectador por medio del tiempo latente, aquel sugerido por los personajes. Así ocurre para informar de los inicios del proyecto colonizador de Magallanes, lo informa el capitán Williams:

Esto es lo que soñó don Bernardo O’higgins. Antes de emprender este viaje, tuve en mis manos las cartas que él le escribió al presidente Bulnes. En todas ellas está patente su fe en Magallanes. No se lee en ellas otra palabra: Magallanes, Magallanes, Magallanes. El sueño de sus últimos días en Montevideo fue venir a colonizar Magallanes en cuanto su salud se lo permitiera (p. 131).

De igual modo, se alude a la construcción de la goleta Ancud y las vicisitudes del viaje hasta llegar a la punta Santa Ana: 
F. Domingo- (...) ¿Te acuerdas de lo que pasó en la goleta Ancud cuando veníamos a fundar este fuerte? ¿Te acuerdas del terrible temporal que estuvo a punto de echarnos a pique a mitad del camino? A estas horas nosotros deberíamos estar en el fondo del mar, y el Fuerte Bulnes en la mente de Dios y en los buenos deseos de los hombres, si no hubiera ocurrido un hecho milagroso: siete de los nuestros, encabezados por don Bernardo Philippi, regresaron a San Carlos de Ancud en una chalupa, y luego volvieron con los auxilios necesarios. Siete hombres, Ambrosio, sólo siete hombres en una miserable chalupa abierta, atravesando más de 150 millas de ida y vuelta, en medio de un mar enfurecido... (p. 124).

Esta alusión correspondiente a un tiempo anterior, es en estricto rigor histórica. La dramaturga, sin incorporar acotaciones temporales que den cuenta de la fecha exacta de los hechos, incorpora correctamente los acontecimientos vinculados al proceso colonizador y al dominio sobre el estratégico canal de Magallanes:

Don Luis.- (...) ¿Se han olvidado de que los ingleses, no hace mucho tomaron posesión de las islas Malvinas?... ¿No recuerdan que mientras nosotros llegábamos aquí el gobierno francés acordaba la colonización del Estrecho de Magallanes? (p. 154).

La distancia entre el tiempo de la lectura/representación y el tiempo de la historia representada permite comprender la obra en su carácter retrospectivo, pues la dramaturga invita al receptor a los tiempos lejanos, cuando se configura por el sur el territorio geográfico de la nación.

Logra la representación cercana a los hechos históricos y ubica al lector/espectador ante la obligación de reconsiderar la historia del país con nuevos antecedentes. Sin recurrir a interrupciones en la ilusión de realidad, los saltos temporales permiten condensar los años de la gesta, con "el dinamismo y el rigor épico puesto en circulación por el estreno en Chile, en 1953, de Madre Coraje, de Bertolt Brecht” (Durán-Cerda, 1970, p. 29).

\section{El espacio}

El espacio configurado por Requena está de acuerdo con la configuración espacial del teatro a la italiana, pues el escenario está abierto justo frente al público. Esta distribución que privilegia un punto de vista, contribuye a un alto grado de representación de la ficción, ya que no rompe el pacto de verosimilitud establecido.

Gracias a la concentración de la acción en un único espacio, Fuerte Bulnes, se evita la sucesión de espacios o la simultaneidad de éstos. La elección de los espacios comunitarios del fuerte, tanto como los espacios interiores de las viviendas precarias, son los espacios patentes, descritos tanto por las acotaciones como en los diálogos. 
Cada acto cuenta con la descripción del espacio físico escenográfico, así como también los espacios verbal, corporal, sonoro. Así queda claro en el primer acto: "Sitio que, en el Fuerte, hace las veces de plaza pública. Hay un grupo de colonos reunidos. Murmullo de conversaciones agitadas" (Requena, 1979, p. 119).

Algo similar ocurre en el epílogo, la acotación indica que ha cambiado la realidad del fuerte, junto con mencionar aspectos del espacio corporal: "Al encenderse las luces, nuevamente se ve entre los escombros, a los colonos, salvo Benamina y Remigio, reunidos en torno a Santos Mardones, que está en una eminencia del terreno" (p. 196).

Las acotaciones son grandes contribuyentes de la configuración del espacio. Sin embargo, en los diálogos se encuentran los adjetivos más significativos: "Barro y nieve. Viento y frío" (p. 120), "La tierra es estéril, o bien el viento arrasa con los sembrados" (p. 132), "estamos emplazados sobre un promontorio" (p. 133), "Más ahora que tenemos encima esta plaga última de ratones” (p. 149).

En los diálogos, se expresa y construye el espacio más difícil de hacer visible materialmente sobre el escenario. Permite la recreación imaginativa del espacio por parte del lector/espectador, sobre todo, cuando el receptor primero de la obra fue el público capitalino, por ello el Colono $1^{\circ}$ dice: "El clima de estas tierras no es el de Santiago. Si no terminas de una vez, el frío nos va a matar a todos” (p. 119).

Junto a los espacios patentes revisados aquí, los diálogos también dan cuenta de espacios latentes (contiguos), visibles para los personajes, pero no para los espectadores. Esto ocurre con el espacio de Punta Arenosa o Sandy Point, según la cartografía inglesa.

Punta Arenosa es la antítesis de Fuerte Bulnes: más protegida del viento, con tierras cultivables y disponibilidad de agua gracias al río Las Minas. Pese a las bondades de esta zona, el proyecto gubernamental insiste en poblar Fuerte Bulnes, acorde a una estrategia geopolítica antes que humanitaria. Así lo expresan los personajes, compárese la opinión del representante de la Iglesia frente a la del representante del Presidente Bulnes:

F. Domingo.- (...) Pero si el Fuerte Bulnes hubiera sido emplazado un poco más hacia el Atlántico, en la Punta Arenosa, tendríamos tierras más feraces y hasta minas de carbón, y eso es muy importante (...)

Williams.- ¿El Fuerte... en la Punta Arenosa? No, no. Imposible. (...) Además estamos emplazados sobre un promontorio y eso es muy importante para defenderse de los indios en caso de ataque (p. 133).

Este juego de antítesis entre Fuerte Bulnes y Punta Arenosa, no solo resalta las enormes dificultades que implica el establecimiento humano en el primer espacio, sino que también la subyugación de los colonos ante las políticas de Estado en pro de la nación.

El capitán Williams promueve el sacrificio humano en pos del proyecto. De igual modo, Fray Domingo lo hace desde el púlpito. Los gobernadores siguientes habrán de respetar 
la misión original. Entre los colonos, prima la disidencia, ellos discuten la viabilidad del proyecto colonizador, mientras los demás apuestan por el autoconvencimiento, como en los versos compuestos por un astillero y recitados por Ignacia al modo de poema épico:

\author{
Tenemos un buen castillo \\ y una buena fortaleza \\ dándole fuego a la pieza \\ estamos bien atrincherados \\ se rompe el fuego graneado \\ al ruido de las cadenas \\ damos las últimas descargas \\ viva la nación chilena (pp. 129-130).
}

La dicotomía espacial solo se romperá en el acto III con el incendio y muerte de Ambrosio y Benamina, que hará que Santos Mardones, solo por vez primera de parte de una autoridad de gobierno, permita el traslado para construir Punta Arenas. Sus palabras finales en el epílogo otorgan sentido al espacio de Fuerte Bulnes: "ha abierto un camino: el camino de Chile en estas latitudes... No habremos sido un buen fin, pero hemos sido un buen eslabón. Y eso es lo importante" (p. 197).

Requena construyó muy bien los espacios patentes de Fuerte Bulnes, también los contiguos. Fiel a su rigurosidad histórica, incorpora un espacio ausente o autónomo, invisible tanto para el público como para los personajes: Ciudad del Rey Felipe o Puerto del Hambre.

Por las palabras del personaje Colono $2^{\circ}$ se da cuenta del espacio anterior al fuerte:

Yo sé que muchos, antes que nosotros, han tratado de colonizar estas tierras. En este mismo lugar en que estamos, sin ir más lejos, los españoles fundaron hace tres siglos una colonia. ¿Han olvidado cómo se llamó esa colonia? ¿Con qué nombre se la recuerda?... Con el nombre de Puerto del Hambre, porque todos los que la formaron dejaron sus huesos en estos mismos terrenos (p. 121).

La incorporación de este espacio, tan lejano al tiempo de la fábula y al tiempo de la representación, tiene múltiples sentidos. Primero, intensifica la fuerza natural de la geografía de Magallanes, lo que aporta también en la comprensión de la colonización como una gesta heroica.

La crítica de Durán-Cerda considera que la obra no logra "trasponer aún en gran medida el diseño naturalista" (1970, p. 29), mirada opuesta a la de Piña, para quien Requena logra, progresivamente, escapar de un "costumbrismo más o menos retratista, huyó de la pura recreación de narraciones legendarias y de aspecto folclorista” (2008, p. 11). El análisis dramatológico concluye que hay una superación del drama de ambiente, 
porque la propuesta de Requena pone al espacio en sintonía con el esfuerzo humano de los colonos.

No es casual que el Fuerte Bulnes haya sido emplazado en el mismo sitio del fracasado proyecto de la corona española. La capital, Santiago, no logra dimensionar las características y condiciones que impone el espacio de Magallanes. Por eso, la elección de emplazar Fuerte Bulnes y mantenerlo en el mismo lugar del Puerto del Hambre es conflictiva y reivindicativa para los colonos.

Los espacios de Fuerte Bulnes, Punta Arenas y Puerto del Hambre contribuyen con mayor fuerza a comprender el sentido de la obra de Requena. La escenificación de los tres espacios busca instalar su representación en el espacio de la capital, para visibilizar ante los espectadores, el espacio desconocido de Magallanes, pues el público de esta obra fueron los santiaguinos de 1955 que asistieron al Teatro Experimental de la Universidad de Chile.

\section{Personajes}

El reparto de personajes se encuentra en la dramatis personae al inicio de la obra: una larga lista que considera a las autoridades civiles, militares y religiosas, junto a la presencia numerosa de colonos, hombres y mujeres, tanto como artilleros e indígenas.

Veintinueve personajes individualizados más otro tanto que ayudan a configurar el espacio como si se tratara del de una epopeya colectiva. El número es importante para dimensionar el proyecto dramatúrgico representativo de Requena y los esfuerzos escénicos que asume el teatro de la Universidad de Chile.

El escenario se transforma en el fuerte, pero también es habitado, con la mayor representatividad, con los personajes que pasaron por ahí en sus casi seis años de funcionamiento. Un primer grupo está compuesto por las autoridades, personajes históricos, quienes otorgan la rigurosidad histórica que buscó la dramaturga: el capitán Williams, Fray Domingo (sacerdote), los gobernadores Pedro Silva y Santos Mardones. Un segundo grupo corresponde a los colonos, hombres y mujeres de Chiloé, quienes fueron elegidos por ser los chilenos más australes y, por tanto, quienes podrían aclimatarse de mejor forma a Magallanes. Por último, aquellos que tienen menor individualización: soldados (artilleros) y los indígenas del lugar, que son nombrados como indios en los diálogos y acotaciones.

Debido al intento de representar la totalidad del tiempo de Fuerte Bulnes, la dramaturga configuró la aparición del abultado número de personajes de acuerdo a tres momentos: años de fundación, años de establecimiento y dificultades, años del ocaso y destrucción del fuerte.

Es así como personajes del acto I no tienen más participación en los actos siguientes o se incorporan nuevos personajes en el acto III. Sin embargo, vale destacar a los personajes que se mantienen durante toda la obra, corresponde al sacerdote y a un 
grupo de colonos de origen chilote ${ }^{8}$, entre los que se encuentran tres mujeres: Ignacia, Venancia y Benamina. No parece casual que tres mujeres tengan no solo las mayores apariciones en la configuración del reparto, sino que también participan en el desarrollo del conflicto.

La figuración de Benamina es la más destacada entre las mujeres del fuerte. Es una mujer casada, comprometida con el proyecto colonizador desde sus inicios, así lo manifiesta: "Yo tenía mi azúcar, mi yerba, mis huevos, mis gallinitas, de un todo. Pero un día le oí decir unas cosas tan bonitas al capitán Williams sobre sus tierras que iban a colonizar, que poco a poco me fui entusiasmando y terminé entusiasmando a éste también” (Requena, p. 136). Con su embarazo, los demás personajes la reconocen como el "símbolo de la fertilidad" en esas tierras. Transformada en símbolo para la comunidad, la muerte de su hijo recién nacido la convierte en el símil de esas tierras, pues nada puede crecer bajo la inclemencia del viento y el frío.

Interesa destacar la incorporación del personaje de Benamina en el significado tradicional otorgado a la mujer, esto es, como gestora de vida, comparada con la tierra en su figuración de madre también. Requena configuró los personajes mujeres según la participación cívica que tenían para los años del siglo XIX chileno, cuando no eran sujetos de derecho, ni de participación en la vida política y social, a menos que ocurriera en el interior de la vida familiar. Esto queda más claro en el epílogo, en el que no hay participación de las mujeres, solo diálogos de las autoridades y personajes hombres.

De igual modo, Requena incorpora una escena cruda y vigente: un hombre golpea a su esposa, ante la preocupación de los demás miembros de la comunidad. La mujer ha conseguido más comida para su marido: "Porque yo me consigo raciones suple con los soldados... Por eso ando rondando por el cuartel, y por eso me llevo a sonrisitas con los soldados. Y si no fuera así ya nos habríamos muerto de hambre" (p. 159). Sin embargo, lo que sorprende a todos es la justificación de la mujer cuando los demás se interponen: "Y pa' eso es mi marío. Pa’ pegarme. Si Cuina me pega, es porque es mi marío, pu” (p. 160).

El trabajo dramatúrgico de Requena escenifica que la gesta chilena sobre Magallanes fue sostenida por hombres y mujeres chilotes, al otorgarle presencia en todos los actos, y por tanto, de principio a fin en la existencia del fuerte. Junto con ello, la dramaturga hace visible las condiciones que restringen a la mujer de 1843, pero también a las mujeres de 1955 (año de estreno de la obra).

Otro personaje mujer es Onahe. Hija de indígena con el proclamado cacique Santos Centurión, nacido en Uruguay. Pese a que no hay detalles sobre los tehuelches, grupo aborigen

8 Para Castedo-Ellerman, la obra escenifica cómo "un grupo de chilenos heroicos se instala en el Sur para establecer que esas tierras australes pertenecen a Chile” (p. 103). Esta afirmación minimiza el origen y condición de aquellos “chilenos heroicos”. En primer lugar, Requena evidencia de modo claro e insistente que los colonizadores fueron chilotes, quienes solo después de 17 años se integraban a Chile bajo acuerdo del Tratado de Tantauco (1826). Estos chilenos nuevos son el sostén del proceso colonizador chileno, pese a la invisibilización de su gesta y compromiso con los destinos del país. 
al que pertenece, su incorporación destaca por la elección de este personaje enamorado del joven chileno Sebastián. Su figura otorga el toque romántico al conflicto central, junto con un matiz exótico que ve en las mujeres indígenas una belleza particular y enigmática.

Otro de los personajes patentes, cuya aparición lo ubica en todos los actos y el epílogo, es Fray Domingo. Su rol como sacerdote es fundamental no solo para la comprensión del proceso evangelizador de las campañas colonizadoras en América, sino que también del apoyo que brinda a los gobernadores. En este personaje, Requena plantea el modo en que el poder religioso sirvió al poder civil, guarda en sus diálogos toda la ideología nacionalista que anima el proyecto de colonización.

Es un conocedor de las condiciones que afectan al fuerte y teme que el proyecto fracase para pérdida del desarrollo del país. Se adelanta a los hechos y actúa para convencer a los colonos de lo valioso y trascendente que resulta su permanencia dentro del fuerte. Cuando el capitán Williams visita el fuerte, se informa no solo con el gobernador Pedro Silva, sino que también con Fray Domingo. Este acto es significativo, pues revela la fuerza del poder eclesial junto al poder civil, pese a que el mismo Fray declare con modestia que su misión es tan solo evangelizar a los indios.

Como representante de la fe, el sacerdote concibe la vida como un sacrificio, cruces que Dios entrega y que deben ser cargadas con la mayor resignación. Sus consejos siempre son una exhortación, como la que da a Benito: "Dios te ha mandado esta misión, y debieras estar feliz con ella, en vez de quejarte porque no tienes el estómago lleno" (p. 153).

La participación de Fray Domingo en el proyecto colonizador, para bien de la nación, tiene sentido en la medida que el personaje considera que el dominio de Chile sobre Magallanes nace primero de un plan divino, tanto para el país como para sus ciudadanos, todos hijos de Dios. Su concepción es coherente con la creencia de la Iglesia en un plan divino de salvación, visión casi inalterable en la historia de occidente. Lo relevante es su permanencia junto al gobierno, quien permite y financia su participación.

Visto así, sus palabras son comprensibles cuando habla a los colonos: "significaría la ruina definitiva de esta empresa que Dios nos ha deparado para ennoblecer nuestras vidas" (p. 123). Requena visibiliza esta dualidad, un joven Estado laico que se vale de figuras como las de Fray Domingo, personaje patente y presente durante todo el tiempo de la obra, por sobre las apariciones de las figuras políticas y administrativas, claro ejemplo del dominio y permanencia de la Iglesia en la historia de Chile.

Particular resulta la aparición de personajes ausentes, meramente aludidos y que todos ellos corresponden a figuras políticas decisivas en la historia nacional. Aquí se encuentran O’Higgins y Manuel Bulnes, caracterizados como prohombres preocupados por los destinos de la nación y la grandeza de la patria. Ellos se ubican fuera de Magallanes, desde Perú y Santiago, respectivamente, desde allí imaginan los destinos de Chile.

El capitán Williams los representa, pero después de su visita en el acto I, se convierte en un personaje ausente. Con él desaparece la representación del poder central. Su ausencia 
reflejará el abandono con que el gobierno somete a los colonos, por eso las palabras del Colono 1": "Yo ya no les creo nada. Parece que las remesas nos las mandaran sino cuando se acuerdan" (p. 143). Todo terminará con el incendio del fuerte, pero antes que eso, con las continuas deserciones de colonos y soldados para instalarse en Punta Arenas.

Requena nomina a los nativos como indios. Pareciera desconocer la carga semántica que conlleva, porque utiliza la palabra sin complejos y equivalente a indígenas, aborígenes o nativos.

Lo que primero se destaca es su aparición como conjunto, sin individualización. Así son nombrados en la dramatis personae del inicio y en las acotaciones. Salvo Onahe, quien encarna la representación romántica de la belleza exótica, capaz de desorientar a un joven chileno y cristiano. Principal preocupación de Fray Domingo, en todos los actos, porque ya desde el inicio temía por las consecuencias de la belleza de la muchacha, la bautizó con el nombre cristiano de Javiera Carrera, con ello le imprimía el compromiso con la patria de la homenajeada.

En un par de diálogos, insignificantes pues siempre son nombrados como indios, se les reconoce su pertenencia étnica: tehuelches. De los distintos nombres, Requena escogió uno de generalización media, entre patagones y aónikenk. No hay descripciones de sus ropas, de sus actos y, menos aún de sus tradiciones; son personajes que aparecen portando simplemente su presencia.

Los tehuelches aparecen como preocupación en tanto pueden convertirse en amenaza para el fuerte. La estrategia de los distintos gobernadores es la convivencia pacífica en la medida que la "política de apaciguamiento" de Fray Domingo tuviera resultados. Parece ser que el trabajo histórico de la narración de la gesta de Fuerte Bulnes sobre Magallanes realizado por la dramaturga es de una rigurosidad y completitud mayor que el de la representación del mundo indígena.

Tehuelches resultan personajes secundarios y circunstanciales, necesarios para la ambientación y el dinamismo del ritmo del drama, pues solo aparecen violentos cuando ha desaparecido Onahe, quien huyó por amor.

Este segundo plano de los tehuelches es mayor si se considera que las órdenes son dadas por el cacique Santos Centurión, ex soldado de las huestes independentistas y que ha hecho vida con los indígenas. Entonces, las figuras de los "indios" aparecen como pacíficas, sin capacidad de hablar, manipuladas por un afuerino que ha actuado movido por la ira y el orgullo personal.

El último gobernador, Santos Mardones, logra apaciguar a Santos Centurión con la fuerza de su investidura política y militar. Tanto para Centurión, como para los tehuelches por extensión, Santos Mardones es la autoridad en esas tierras, el resto solo son pobladores.

\section{Visión}

En su conjunto, Fuerte Bulnes no está configurada como una obra que busca establecer una distancia representativa; al contrario, busca establecer la mayor ilusión de realidad, pese a que ya eran conocidas las obras de Brecht en Santiago. Lo logra con la incorporación de una 
variedad de elementos que configuran de manera clara la representación de Fuerte Bulnes, principalmente la rigurosidad histórica de los acontecimientos ocurridos, al igual que de los personajes y la configuración de los espacios.

Desde el punto de vista temático, los personajes destacados son los colonos chilotes. Su presencia constante durante toda la obra muestra sus aspectos más humanos, como la profunda contradicción de debatirse entre continuar la misión colonizadora y de soberanía en Fuerte Bulnes o Punta Arenosa. Sus diálogos evidencian la ambición, los sueños, egoísmos implicados en una tarea que excede sus fuerzas. La configuración humanizada de estos personajes permite la empatía del lector/espectador, porque siente de cerca los motivos humanos representados, en particular, el amor romántico de Sebastián y Onahe, el amor de madre de Benamina por su hijo muerto.

En cambio, los personajes aludidos, O'Higgins y Bulnes, conservan la idealización que la historiografía tradicional les ha otorgado. O’Higgins, el padre de la patria, preocupado de la seguridad territorial de la nación; Bulnes, Presidente destacado en la consolidación de la República. Sus configuraciones no producen extrañeza y facilitan la catarsis, gran objetivo del drama, pues el espacio y el tiempo de la obra están en coherencia con el tratamiento histórico de los personajes.

El desarrollo del drama histórico desemboca en la comprensión del espacio magallánico, en su magnitud natural y en la valorización del proceso histórico que involucró la gesta humana, antes que institucional, de incorporar nuevos territorios a la nación.

Ante personajes humanizados que se enfrentan voluntariamente para la colonización y construcción del Estado-nación, el lector/espectador empatiza. La obra apuesta por elevar la perspectiva cognitiva del público, pues su gran misión ha sido reconsiderar la idea de Chile en su sentido más amplio, geográfico e histórico, ya que con la representación de la gesta de la Goleta Ancud valoriza de modo distinto el territorio e incorpora otros hechos históricos importantes para la independencia y soberanía, más allá de 1810 y 1818.

\section{CONCLUSIONES}

El análisis dramatológico de Fuerte Bulnes coincide con la lectura de la obra como drama histórico, en tanto hay un apego a los hechos históricos de la incorporación de Magallanes al territorio nacional narrados por la historiografía oficial. El tiempo y el espacio de la obra ponen en escena un momento y lugar desconocido para Santiago, en que se evidencia la participación de los próceres de la Independencia y organización nacional -O’Higgins, Bulnes, Williams- para establecer los límites de la nación a partir de la herencia colonial.

Este apego a la historiografía permite que lectores y espectadores amplíen su noción de la historia de Chile. Su fin didáctico plantea reconocer que la construcción del país y fijación de límites es un proceso posterior a la proclama independentista y en la que participó un grupo particular de chilenos. 
Castedo-Ellerman vislumbró de modo acertado el realce de los personajes. Sin embargo, el análisis complementa la crítica precedente al demostrar que en la configuración de los personajes son hombres y mujeres chilotes quienes sostienen la gesta colonizadora. En particular, son las tres mujeres quienes organizan la convivencia al interior del fuerte e incluso actúan para modificar las condiciones materiales de su existencia con la inmolación e incendio emprendido por Benamina.

Esta obra de Requena es más que un drama histórico. En el marco de los hechos históricos, la dramaturga se esfuerza en reconfigurar el imaginario del sur de Chile. Intenta corregir la serie de omisiones y tachaduras a que ha estado sometida la historia austral del país, para inscribir la gesta colonizadora de la goleta Ancud en los esfuerzos por la construcción del país y por monumentalizar la participación de hombres y mujeres de Chiloé, recientemente ciudadanos chilenos.

Tras la revisión de las categorías de ficción, diálogo, acotaciones, tiempo, espacio y personajes propuestas en el marco teórico de García Barrientos, el comentario dramatológico deja en evidencia la riqueza de la escritura dramática de María Asunción Requena. La obra está configurada para escenificar los hechos históricos: la acción patente; sin embargo, los diálogos permiten incorporar aquello que no es posible representar sobre las tablas, sino solo aludir.

La permanente incorporación de lo latente y lo ausente deviene en un juego dramático que pone a Fuerte Bulnes en primer plano y sitúa a Santiago como espacio de lo ausente, porque su preocupación administrativa no alcanza para los territorios extremos y descuida a sus ciudadanos.

La representación literario/teatral de la zona austral de Chile es limitada. En esta corta tradición, la dramaturgia de María Asunción Requena consagra la escenificación de un territorio desconocido para el centro político y administrativo del país. ¿Cómo se entiende hoy el territorio de Chiloé, Aysén y Magallanes en la dramaturgia chilena después de la trilogía del sur de Requena?

Urge una revisión de la dramaturgia chilena contemporánea que tematiza asuntos históricos y territoriales de la Patagonia chilena, para hacer dialogar las distintas representaciones del sur. Por ejemplo, una lectura dialógica y comparada con la obra $E l$ abismo de los pájaros (2017) de Fabiola Ariadna Ruiz, pues tiene como asunto el mítico Puerto Edén, abordado anteriormente en Ayayema, de María Asunción Requena.

\section{REFERENCIAS}

Abraham, L. (2015). [Revisión del libro La razón pertinaz. Teoría y Teatro actual español, de J. L. García Barrientos]. Cuadernos del CILHA, 22, 114-116.

Cánepa, M. (1966). El teatro en Chile. Desde los indios hasta los teatros universitarios. Santiago de Chile: Editorial Arancibia Hermanos. 
Carrera, M. (2014). [Revisión del libro La razón pertinaz, de J. L. García Barrientos]. Itinerarios, 20, 231-235.

Castedo-Ellerman, E. (1982). El teatro chileno de mediados del siglo XX. Santiago de Chile: Editorial Andrés Bello.

Durán-Cerda, J. (1963). El teatro chileno moderno. Separata de los Anales de Universidad de Chile, 126, 168-203.

Durán-Cerda, J. (1970). Teatro chileno contemporáneo. México: Aguilar.

Fernández, T. (1976). Apuntes para una historia del teatro chileno: los teatros universitarios (1941-1973). Separata de Anales de Literatura Hispanoamericana, 5, 331-347.

García Barrientos, J. (2007). Análisis de la dramaturgia. Nueve obras y un método. Madrid: Fundamentos-RESAD.

García Barrientos, J. (2012). Cómo se comenta una obra de teatro: ensayo de método. México: Paso de Gato.

García Barrientos, J. (2018). Análisis de dramaturgia uruguaya actual. Madrid: Ediciones Antígona.

Henríquez, P. (2010). Figuraciones del indígena fueguino: Ayayema de María Asunción Requena. Antología: Un siglo de dramaturgia. Tomo I: Periodo 1950-1973. Santiago de Chile: Comisión Bicentenario.

Luzanto, P. (1994). María Asunción Requena (1915-1986). En B. Rojas \& P. Pinto (Eds.), Escritoras chilenas. (Vol. I). Concepción: Cuarto Propio.

Muñoz, L., \& Oelker, D. (2014). Diccionario de movimientos y grupos literarios chilenos. Desde el movimiento literario de 1842 hasta el teatro de la década del 50. Concepción: Editorial Universidad de Concepción.

Olivares, P. (2008). [Revisión del libro Análisis de la dramaturgia. Nueve obras y un método, de J. L. García Barrientos]. Dialogía, 3 , 273-285.

Piña, J. (2008). Prólogo. Restitución de María Asunción Requena. En M. A. Requena, Fuerte Bulnes; Chiloé, cielos cubiertos. Santiago de Chile: Editorial Zig-Zag.

Piña, J. (2014). Historia del teatro en Chile. 1941-1990. Santiago de Chile: TaurusRequena, M. (1979). Ayayema- Fuerte Bulnes- Chiloé, cielos cubiertos. Santiago: Nascimento.

Requena, M. (1979). Ayayema- Fuerte Bulnes- Chiloé, cielos cubiertos. Santiago de Chile: Nascimento.

Ruiz, F. (2017). El abismo de los pájaros. Artescena, 3, 1-25.

Villegas, J. (1971). La Interpretación De La Obra Dramática. Santiago de Chile: Editorial Universitaria.

Villegas, J. (1995). María Asunción Requena: éxito e historia del teatro. Latin American Theatre Review, 28, 19-37. 